\section{Efficient financing for your dream practice}

The support of an experienced finance team is always worthwhile when seeking a loan to buy a dental practice. DE Finance provides a range of services to help buyers secure funding with the most competitive terms.

The team can analyse your assets and liabilities to provide you with a theoretical budget to use when shopping for your dream practice. Through loan stress testing, they can also assess the viability of practices as you view them and offer reliable advice on likely debt capacity.

Managing the entire process on your behalf, DE Finance acts as lynchpin between you, your solicitor and the lender for the most efficient transaction.

For more information visit www. dentalelite.co.uk,email info@dentalelite. co.uk or call 01788545900 .

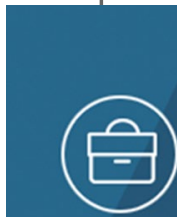

\section{Dental Practice} Finance

\title{
The service you expect and deserve
}

Clark Dental is renowned within the dental sector for its commitment to delivering an unparalleled client service. The team are highly experienced in transforming practices of all sizes, providing exceptional turnkey surgery designs and supplying the latest dental technology from world-leading brands.

What differentiates the Clark Dental team is that their service doesn't just stop at the point of sale. Whether you require maintenance, repair or technical support, you can be confident that they will be on hand even after project completion to ensure you have everything you need to do your best work.

For more information call Clark Dental on 01268733 146, email info@clarkdental. co.uk or visit www.clarkdental.co.uk.

\section{Ultimate peace-of-mind}

To support dental professionals, W\&H dental turbines offer features to minimise the production of contaminated aerosols in practice.

These handpieces feature a patented hygiene head with an anti-retraction system
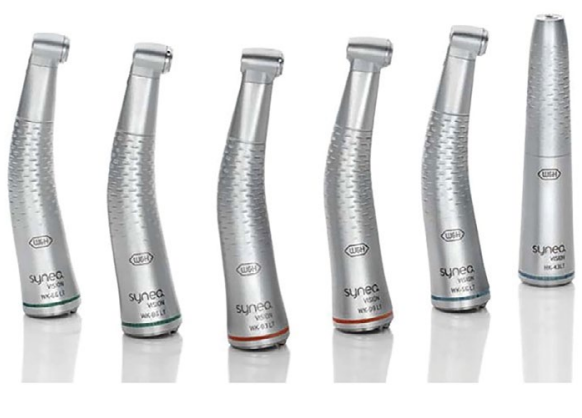

that is designed to limit the number of aerosols being sucked back into the turbine as the rotor slows to a stop.

Dental turbines from W\&H have also been optimised with an anti-retraction valve within the turbine itself, which prevents the

backflow of potentially contaminated water via the turbine's waterlines to the central water supply system.

This facilitates the highest infection control standards for ultimate peaceof-mind among both staff and patients.

Discover the full range of $\mathrm{W} \& \mathrm{H}$

handpieces via the website at www. wh.com/en_uk or call 01727874990 or email office.uk@wh.com.

\section{New education programme launched}

The MiSmile Network has announced the launch of the MiSmile Academy, an online, entry level education programme which introduces the highly successful MiSmile growth strategy. The Academy will offer greater access to the MiSmile Network's methodologies for general dentists who are unaffiliated with the Network for the first time.

The MiSmile Network is an umbrella organisation, comprising 80 independent dental practices located across the UK, each with a vested interest in growing their Invisalign expertise and case submissions. Within a year of joining, members report an average of $126 \%$ growth and between them have completed over 15,000 Invisalign cases.

While the MiSmile Network members all have some experience treating patients with the Invisalign system when they join, the additional benefits of membership include ongoing access to the latest business and clinical training which means that they are able to treat more interesting and challenging cases with greater confidence.

Each quarter, a new intake of delegates will benefit from a three-month programme which will give them privileged access into the MiSmile Network strategies. The typical candidate to benefit from the Academy programme will be a practice principal or associate who is ambitious to step up a gear, to grow their case numbers and their practice.

Each topic on the Academy programme syllabus is delivered by a roll-call of recognised industry experts; so lead generation is taught by KMG and Chris Barrow; lead conversion by DenGro, Laura Horton, Dr Kunal Patel and Lucy Patel; clinical confidence by Dr Adriana Garro and Dr Oliver Smart, and profitability by the
MiSmile Network team. The weekly sessions are delivered live over a private Zoom platform and are also recorded and made available on a secure platform for course participants to revisit. A WhatsApp group and online support platform is also available for each cohort to provide an additional level of mutual support and a sense of the community engendered amongst Network members.

For more information about joining the next MiSmile Academy cohort visit https:// academy.mismile.co.uk.

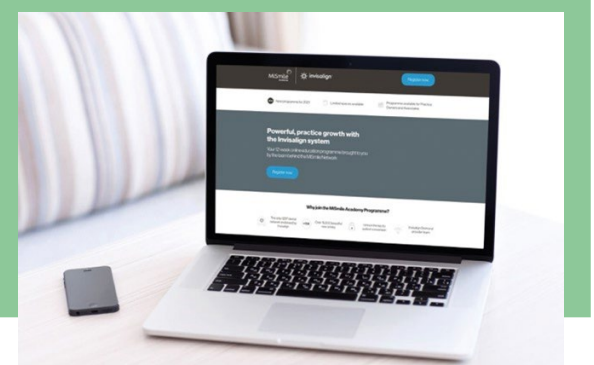

